\title{
PERSPECTIVAS
}

Artigo convidado

Versão original

DOI: http://dx.doi.org/10.1590/So034-759020200507

\section{FUTURO DO TRABALHO NO BRASIL: CUIDAR DAS INSTITUIÇÕES}

\section{INTRODUÇÃO}

Qualquer reflexão sobre o futuro deve ser também sobre a passagem do tempo. Nesse sentido, é preciso delimitar minimamente as condições mais importantes do presente para especular e projetar cenários prováveis. Todavia, a apreensão daquilo que é mais relevante no presente é tarefa difícil. 0 mundo da gestão pública e privada debate-se com isso, tentando antecipar os fatos e amoldar o futuro por meio do planejamento.

Mesmo com toda tecnologia disponível para processamento de dados, a busca por previsibilidade ou, de outra forma, de redução da incerteza continua sendo uma tarefa como a de Sísifo empurrando sua pedra montanha acima. Quando imaginamos que a busca está completa pela chegada do futuro, notamos que permanecemos no presente e cheios de dúvidas. Nesse instante, nossa pedra novamente rola ladeira abaixo.

De todo modo, assim como Sísifo não deixa de empurrar sua pedra para o topo da montanha, não paramos de pensar o futuro. Nesse sentido, este artigo serve-se do trabalho de Gazi Islam que o acompanha nesse mesmo número e seção da RAE e comunga das mesmas preocupações ali apresentadas. 0 autor observa o cenário internacional e aponta três arenas em que ocorrerão lutas importantes quanto ao futuro do trabalho, os seus limites, a solidariedade e os ganhos derivados do trabalho. Ali são apresentadas implicações quanto ao espaço e tempo do posicionamento do trabalho; ao arranjo do trabalho na produção e na sociedade e; ao status econômico do trabalho. Nosso estudo realiza uma reflexão sobre o futuro do trabalho no Brasil a partir de um aspecto comum e transversal às três arenas apontadas por Islam (2020): a importância das políticas públicas e, em última instância, das instituições de regulação e suporte ao trabalho no País.

Do ponto de vista das políticas públicas e das instituições do trabalho, em nível internacional, espaços privilegiados como os da Organização Internacional do Trabalho (OIT) têm se pautado em apontar as tensões antigas e novas trazidas pelo andamento da economia em escala global. No caso da OIT, com escopo abrangente, a agenda do trabalho decente vem sendo propagada há mais de 20 anos com o intuito de promover o acesso aos mercados de trabalho, a igualdade de oportunidades e o diálogo social como forma de viabilizar esses objetivos (International Labor Organization [ILO], 2019). No nível nacional, as questões propostas pela competição em escala global e a transição tecnológica têm levado ao estabelecimento de políticas nacionais de inovação vinculadas à formação compatível de capital humano, ou seja, também alcançando o mundo do trabalho em países como Alemanha, Estados Unidos e China (Arbix, Salerno, Zancul, Amaral, \& Lins, 2017).

Para além das questões de fundo apresentadas por Islam, a discussão sobre o futuro do

\section{Universidade de São Paulo, Faculdade de Economia, Administração, Contabilidade e Atuária, São Paulo, SP, Brasil \\ DE AMORIM ${ }^{1}$ \\ wamorim@usp.br \\ 0000-0002-0983-1447}

lho no Brasil tem, em seu presente, condições extremamente desafiadoras no que se refere às políticas públicas e suas instituições. 
Como primeiro aspecto, vêm os efeitos da prolongada crise econômica que afetava o mercado de trabalho brasileiro desde meados de 2014 até o início de 2020. Esse período registrou simultaneamente elevação da desocupação, da subocupação, do trabalho informal e o reforço de desigualdades de toda ordem. Relacionada a essa crise e também, genericamente, à inserção da economia nacional na globalização, em outro elemento, vemos a aceleração da transição tecnológica com efeitos visíveis sobre a estrutura ocupacional do mercado de trabalho tanto no seu topo quanto na sua base. Entre esses efeitos, nota-se a elevação do número de trabalhadores autônomos formais (como prestadores de serviços a empresas) e, principalmente, informais. Um terceiro elemento importante é o ingresso decisivo do País em um ambiente laboral inclinado para a flexibilização das suas formas de contratação, com a aprovação e entrada em vigência da Reforma Trabalhista de novembro de 2017. A simultaneidade desses elementos contou um contingente de dezenas de milhões de pessoas que compõem a oferta de trabalho no Brasil em um quadro de desproteção em consolidação a partir de 2014. Ou seja, os elementos do presente e/ou do passado recente são impulsionadores de um futuro nebuloso e pouco otimista para o trabalho neste momento.

Neste artigo, proponho que a reflexão do futuro do trabalho no Brasil tome por base a evolução das instituições do trabalho no País em seu sentido mais geral para pensá-las como suas condicionadoras. Nossas justificativas para esta abordagem são o encolhimento recente do espaço institucional em que se discute o amparo ao trabalho no Brasil e o risco que isso oferece às possibilidades de desenvolvimento sustentável nacional.

\section{MERCADO DE TRABALHO NO BRASIL: INSTITUCIONALIDADE INCOMPLETA}

Não cabe, neste trabalho, uma recuperação exaustiva a respeito do mercado de trabalho no Brasil, mas é importante tocar em pelo menos três de seus aspectos: sua formação, características de sua regulação e evolução até meados da década de 2010.

A formação de um mercado de trabalho está intimamente relacionada com a estrutura e o comportamento da economia e da sociedade de um país. Por causa da escravidão, a constituição do mercado de trabalho no Brasil foi um fenômeno tardio se comparado aos países desenvolvidos.

O mercado de trabalho brasileiro começou a se constituir como tal no início do século XX, com a intensificação da urbanização de áreas como as da cidade de São Paulo. Naquele período, verificavam-se os primeiros movimentos de uma industrialização voltada basicamente para o consumo interno, principalmente na cidade de São Paulo. Naquele momento, havia a chegada de um contingente crescente de imigrantes, inicialmente para o trabalho no setor agrícola cafeeiro, mas logo redirecionado para o assalariamento nas cidades.

A libertação da mão de obra escrava ocorrida em 1888 teve efeitos continuados sobre o mercado de trabalho. Em primeiro lugar, sua libertação ocorreu sem nenhum tipo de política compensatória ou de apoio aos que, tornando-se formalmente homens livres, precisavam buscar seu sustento. Os ex-escravos e seus descendentes, por menos qualificados que fossem, também se integraram às condições estruturais de um mercado de trabalho nascente. A combinação entre a demanda por trabalhadores de uma indústria e a oferta crescente de mão de obra conformou gradativamente um mercado de trabalho urbano assalariado no País (Barbosa, 2008). A atração exercida por esses núcleos urbanos estendeu-se inclusive a outras regiões do País e criou uma dinâmica de movimentação de pessoas do interior para as capitais e de outras regiões em direção ao Sudeste.

Dos anos 1930 em diante, o assalariamento urbano somou-se ao surgimento da legislação trabalhista. A Consolidação das Leis do Trabalho (CLT) resultou da elaboração progressiva de normas legais a partir de 1936, que concederam aos trabalhadores uma série de direitos quando da sua contratação pelas empresas.

Essa mesma legislação impôs forte controle estatal sobre a ação sindical no que se refere ao funcionamento e financiamento das entidades representativas de trabalhadores e empresários. Essa legislação surgiu em um período autoritário (Estado Novo), ainda antes que o próprio movimento sindical se constituísse como ator relevante a ponto de levar suas reivindicações ao debate público e fóruns das decisões de Estado (Gremaud, Saes, \& Toneto, 1997).

A CLT inaugura institucionalmente a estrutura de proteção social do Estado brasileiro aos trabalhadores em um momento particular ao Brasil, não muito distante do surgimento da preocupação com a questão do trabalho em termos globais representada pela criação da OIT em 1919. A estrutura da CLT prioriza a proteção ao assalariamento urbano e caracteriza-se, ao longo do tempo, pela sua baixa efetividade na prática (Dedecca, 2005).

A CLT definiu institucionalmente as chamadas regras do jogo para (North, 1991), e, por meio, delas interferiu no ambiente econômico político e social brasileiro. Ao seu modo, a legislação trabalhista brasileira tornou-se uma estrutura estável que condicionou os movimentos dos atores do trabalho, reduzindo suas incertezas. Sob sua influência, as condições mais favoráveis de contratação do trabalho urbano nas regiões industrializadas 
atraíram permanentemente, por décadas, trabalhadores das regiões mais pobres e/ou rurais. Com essas condições institucionais, o mercado de trabalho nacional engendrou um permanente excesso na oferta de mão de obra.

Com o passar dos anos, consolidou-se um mercado de trabalho pautado pela desigualdade e heterogeneidade regional em termos de qualificação, rendimento e qualidade de contratação dos trabalhadores. Ainda que o dinamismo na geração de empregos tenha se constituído em outra forte característica do mercado de trabalho brasileiro, esse mesmo mercado sempre teve grande informalidade, ou seja, contratação do trabalho sem o registro em carteira de trabalho nem cumprimento integral dos direitos dos trabalhadores (Pochmann, 2010). Como a informalidade crescia na proporção em que as empresas de distanciavam do núcleo empregador, que era a indústria, a heterogeneidade também se revelou setorial (Departamento Intersindical de Estatística e Estudos Socioeconômicos [DIEESE], 2012).

O forte desenvolvimento econômico experimentado pelo País no Pós-Guerra aconteceu em descompasso com o desenvolvimento social, posto não terem sido criados mecanismos redistributivos propostos por políticas sociais efetivas. A institucionalidade limitada do mercado de trabalho brasileiro fez com que o desemprego adquirisse características complexas no Brasil, dada a existência de subemprego e/ ou ocupação informal no País (Dedecca, 2005). O segurodesemprego, instrumento clássico de políticas públicas voltadas ao mercado de trabalho, foi criado apenas em 1986 no Brasil, com posterior integração ao conjunto de direitos sociais contidos na Constituição de 1988.

O mercado de trabalho no Brasil teve expansão vigorosa desde o Pós-Guerra, mas conheceu crises no início dos anos 1980 associadas às contingências da economia nacional. Nessa etapa, pela primeira vez, houve crescimento expressivo do desemprego e arrefecimento do dinamismo observado em décadas anteriores quanto à criação de ocupações. Nos anos 1990, uma conjunção de elementos elevou o patamar do desemprego no País a níveis até então desconhecidos. Na primeira metade da década, havia um ambiente hiperinflacionário, e foram notáveis os efeitos da abertura abrupta da economia nacional realizada ainda no início do governo do presidente Fernando Collor. A abertura comercial desestruturou cadeias produtivas inteiras, até então protegidas pela reserva de mercado que caracterizou o modelo de desenvolvimento brasileiro vigente. A taxa de desemprego praticamente duplicou, e o rendimento médio real dos empregados caiu cerca de $20 \%$ no início da década (DIEESE, 2001).

Em 1994, o Plano Real introduziu novas condições econômicas ao País ao derrubar a inflação, apoiando-se na desindexação da economia, elevação dos juros e sobrevalorização cambial. 0 discreto crescimento econômico do período não chegou a exercer influência positiva no mercado de trabalho.

Nessa década, o diagnóstico oferecido pelo governo após 1994 era de que o mercado de trabalho brasileiro se pautava por uma rigidez incompatível com a melhor inserção da economia nacional na agenda da globalização. Com isso, passou a prevalecer uma visão de política pública voltada à maior flexibilização do mercado de trabalho. O fim das políticas salariais e o estabelecimento na legislação da participação nos lucros e resultados e da jornada de trabalho na forma dos bancos de horas foram medidas de flexibilização da contratação do trabalho (Dedecca, 2005). A despeito da perda de poder de barganha provocada pela alta desocupação, os sindicatos ainda conseguiram certo poder de veto quanto ao avanço de mais medidas de flexibilização para a contratação do trabalho (Almeida, 1998).

A partir de meados dos anos 2000 , o mercado de trabalho brasileiro acompanhou a trajetória de crescimento da economia e apresentou dinamismo pela criação de ocupações e diminuição da informalidade. A pressão por mais flexibilidade na contratação do trabalho foi deixada de lado durante os governos do PT. Nesse período, pela sequência de anos com desempenho mais favorável da economia, houve crescimento do volume do trabalho assalariado no setor privado. Os sindicatos ocuparam um espaço importante nas relações de trabalho, e as greves voltaram a fazer parte do cenário laboral (Amorim, 2015; Cardoso, 2014). A informalidade do trabalho diminuiu, sem, no entanto, ser eliminada como característica estrutural do País.

\section{MUDANÇA NO AMBIENTE INSTITUCIONAL DO TRABALHO NO BRASIL}

Em fins de 2014, esse ciclo positivo para o mercado trabalho brasileiro foi interrompido pela crise econômica e a incerteza política no País. O impeachment de Dilma Roussef, em 2016, alterou o jogo de forças na arena política radicalmente. Em termos gerais, os sindicatos perderam espaço no novo governo e, na conjunção dos fatores políticos e econômicos trazidos pela recessão, seu poder de veto nos debates nacionais praticamente se esvaiu. Até que, entre o final de 2016 e 2017, ocorreu a tramitação, aprovação e entrada em vigor da Reforma Trabalhista (em novembro de 2017).

Cabe observar que não se trata de questionar a necessidade ou não de alterar a CLT. Em primeiro lugar, em âmbito internacional, a realização de reformas trabalhistas vinha 
sendo comum em países desenvolvidos ou em desenvolvimento, evidenciando ajustes praticados ao redor do mundo em busca de mais competitividade e respostas às condições da globalização (Adascalitei \& Morano, 2015; Philips \& Eamets, 2007).

Além disso, em âmbito nacional, desde o fim da ditadura nos anos 1980, em várias ocasiões, o debate público mostrou ser importante para a realização de mudanças ou atualizações na longa e complexa legislação que, desde 1943, regulava a contratação do trabalho, a vida sindical e a atuação da Justiça do Trabalho. Nas diversas vezes em que essas alterações foram tentadas, a via proposta foi a de algum tipo de entendimento tripartite, como nos Fóruns Nacionais do Trabalho de 1993 , 2003/2004 (Amorim, 2007), ou mesmo na tentativa de consenso em torno de uma agenda nacional pelo trabalho decente em 2012 (Ministério do Emprego e Trabalho [MTE], 2011). Nessas ocasiões, para além do consenso sobre a necessidade de mudança na legislação laboral, também houve em comum uma espécie de empate ou exercício cruzado de veto das partes envolvidas, em relação às mudanças na organização sindical ou direitos trabalhistas. Desde sempre, pelo forte posicionamento de todas as partes, eventuais mudanças foram marginais.

Em 2017, o jogo institucional foi desempatado. Com a ativa participação das confederações patronais (Confederação Nacional da Indústria [CNI], 2017; MTE, Federação do Comércio do Estado de São Paulo [Fecomércio], 2017) e o apoio da cúpula de momento da Justiça do Trabalho, a reforma trabalhista foi elaborada e aprovada no parlamento, sem chance de resistência. Seu sentido geral era de flexibilização e redução de custos para a contratação do trabalho. Mais de 100 itens da CLT foram alterados para criar novas formas de contratações mais flexíveis, retirar o financiamento oficial dos sindicatos, encolher o alcance da Justiça do Trabalho e dar maior peso à contratação individual do trabalho (DIEESE, 2017; Krein, 2018).

Até então, a institucionalidade de proteção incompleta, que, embora tolerasse a informalidade, ainda regulava direitos de um núcleo do mercado de trabalho, foi mitigada. A perspectiva de que a relação de trabalho acontece, como em uma relação comercial comum, entre atores potencialmente iguais passou a prevalecer na lei.

$\mathrm{Na}$ área sindical, a perda brusca de financiamento praticamente imobilizou as entidades dos trabalhadores. Do ponto de vista das novas formas mais flexíveis de contratação (trabalho intermitente, temporário, e.g.), é possível se afirmar que a continuidade da recessão não chegou a permitir um teste efetivo quanto à maior adesão das empresas. De toda maneira, o piso de direitos quanto à contratação foi reduzido nessas novas modalidades, e as primeiras contratações começaram a acontecer.
Já com relação à Justiça do Trabalho, ainda persiste forte incerteza jurídica quanto a inúmeros aspectos da legislação aprovada. Tais elementos encontram-se certamente ligados ao modo praticamente unilateral como a formulação da nova legislação foi conduzida, sem margem para o apontamento de dúvidas e zonas legais cinzentas.

No nível público, os argumentos favoráveis à reforma eram que a flexibilização da contratação reduziria a burocracia e também os custos de contratação. Apontou-se ainda, como resultado esperado, maior geração de emprego. Pelo conhecimento econômico disponível, isso é improvável, até pelo seu enfoque de cunho microeconômico. Ainda assim, dentro desse princípio, nas franjas da legislação, a rosca sem fim da flexibilização ainda busca formas de baratear a contratação do trabalho pela redução de encargos trabalhistas, em uma visão francamente liberal e orientada ao mercado.

Nesse ambiente, a agenda do trabalho perdeu prioridade. Como exemplo eloquente da perda de prioridade do trabalho, houve a extinção do Ministério de Trabalho em 2019 e sua acomodação em uma secretaria do Ministério da Economia, deixando, na prática, de existir uma orientação mais ativa ou visível do governo na promoção do trabalho. Em um exemplo possível do que isso significa, toda a mobilização recente dos trabalhadores de aplicativos de entregas ou transporte de pessoas vem gerando mais pressões regulatórias no âmbito de Estados e municípios do que propriamente no governo federal. Para um país com as dimensões territoriais do Brasil, isso certamente pode gerar confusão.

Como um rolo compressor, a reforma trabalhista deu-se sem contraponto de outros atores e trouxe um ambiente institucional desconhecido para o Brasil. A perda de prioridade do trabalho no debate público nacional tornou-se, no momento, um dos principais entraves à visualização de um futuro mais promissor para o trabalho no País.

\section{A PANDEMIA: CHOQUE E APRENDIZADO}

Até o início de 2020, a tímida reação da economia brasileira à prolongada crise vivida desde 2014 ainda não havia produzido efeitos expressivos sobre o mercado de trabalho. Em grandes números, 106 milhões tomavam parte no mercado de trabalho. Destes, 93,4 milhões estavam ocupados e 12,5 milhões estavam desocupados. Entre os ocupados, 11,6 milhões eram assalariados informais, 4,9 milhões eram autônomos formais, mas outros 19,3 milhões eram autônomos informais (Instituto Brasileiro de Geografia e Estatística [IBGE], 2020). Ou seja, além de um grande 
volume de desocupados, ainda existiam quase 31 milhões de trabalhadores informais, a descoberto, portanto, de direitos trabalhistas e reafirmando esse traço estrutural do Brasil.

A chegada da pandemia, em fevereiro de 2020, trouxe efeitos conjunturais e estruturais ainda não totalmente mensuráveis, mas certamente devastadores. Ela gerou angústia por encolher drasticamente o horizonte de planejamento dos atores econômicos, sociais e dos indivíduos no mercado de trabalho, e concretizou a inimaginável deterioração de um quadro que já era grave. Em semanas, pelo menos dois movimentos importantes foram verificados. A população ocupada diminuiu em 8,9 milhões de pessoas. Ao mesmo tempo, outros 8,9 milhões de pessoas se retiraram do mercado de trabalho.

Com a paralisação da economia, a pandemia escancarou a precariedade das instituições do trabalho e mesmo das sociais. Além dos assalariados formais que perderam seus empregos e foram atrás do seguro-desemprego, dezenas de milhões sem direito a ele ficaram sem trabalho e renda do dia para a noite e, a princípio, não teriam a quem ou a que recorrer para a sobrevivência.

A gravidade da situação levou o governo a realizar ações emergenciais para manutenção de renda e de emprego na direção de desocupados, autônomos e empregados. Entre os assalariados, surgiu a possibilidade de manutenção de emprego e redução de salário combinada ao acesso aos recursos do seguro-desemprego, bem como a negociação desses termos em acordos coletivos e individuais (conforme o salário recebido) (DIEESE, 2020a).

A inexistência ou inadequação de cadastros da parte do Estado, o pouco preparo e até mesmo convicção da sua estrutura para lidar com a emergência deixaram claro quão incompleta essa institucionalidade era para lidar com essa situação. Em um curto intervalo de tempo, descobriu-se que, além da legião de desocupados, subocupados e informais, havia uma multidão oculta de pessoas sem CPF ou identidade conhecida para as políticas públicas do Estado.

Pode-se argumentar que, pela imprevisibilidade da situação criada pela pandemia, dificilmente qualquer Estado teria como responder em tempo à demanda social emergente. Entretanto, para efeito de reflexão, no Brasil, a pandemia, na prática, concentrou dramaticamente em semanas um cenário que, no mercado de trabalho, já era conhecido desde 2014, de maneira quase naturalizada, sem nenhum anteparo especial planejado ou proposto pelos governos do período.

Mesmo com acento fortemente liberal, o governo viu-se na obrigação de constituir estruturas e políticas para atacar o risco de desagregação social pela fome e penúria. Ou seja, diante de circunstâncias críticas, as sociedades defendem-se por meio das instituições e erigem políticas públicas para defendê-las dos rigores excessivos que visões marcadamente de mercado - e, por isso, contrárias à intervenção - queiram impor (Polanyi, 2012).

As medidas emergenciais tiveram aceitação no meio privado com o surgimento de acordos coletivos regulando a situação de categorias como metalúrgicos, comerciários e dos transportes (DIEESE, 2020b). Além disso, em movimento independente, um grupo expressivo de empresas divulgou iniciativas de garantir empregos no início da pandemia. Já para o auxílio emergencial, a demora e dificuldade de acesso demonstraram as ineficiências na implantação efetiva dessas políticas. A sua continuidade e valores tornaram-se ponto de tensão da política econômica do governo, mas já ocupam também o tabuleiro do debate político. As democracias representativas, mesmo em suas imperfeições, rejeitam e evitam as fomes coletivas (Sen, 2010). Ao seu modo, a brasileira também tentou o mesmo.

Em meio a toda a dureza imposta pela pandemia, talvez esse seja um dos principais aprendizados a respeito do mercado de trabalho brasileiro. É preciso trazê-lo de volta ao centro das prioridades nacionais e aproveitar o momento para remodelar a sua institucionalidade.

\section{O FUTURO DO TRABALHO NO BRASIL: A NECESSIDADE DE UMA AGENDA}

A pandemia mostrou, pela urgência, a necessidade de uma agenda abrangente para o trabalho no Brasil que estabeleça conexão com as condições de modernização da própria economia no futuro próximo. Desse ponto de vista, parte-se do princípio de que se a situação pré-Reforma Trabalhista não era a ideal, tampouco é a de momento.

De saída, vale observar as preocupações da OIT com relação à questão do futuro do trabalho pelo mundo. A entidade propõe o estabelecimento de uma agenda do trabalho centrada no ser humano e assentada no investimento em três pilares: nas capacidades das pessoas, nas instituições do trabalho e no trabalho decente e sustentável (ILO, 2019). No foco deste trabalho, vamos nos concentrar nas recomendações quanto às instituições do trabalho. Para a OIT, as possibilidades de desenvolvimento socioeconômico sustentável estão condicionadas pela busca de um padrão de trabalho decente, a ser definido nacionalmente, mas baseado em diálogo social, regulação e busca do cumprimento das normas vigentes para a contratação como modos de formalização do trabalho, redução da pobreza e da desigualdade. 
Observando diretamente o caso brasileiro, por toda a trajetória histórica até aqui, a questão da informalidade segue sendo um problema a ser atacado. Nos últimos 40 anos, o único período em que a informalidade caiu foi quando o crescimento econômico foi significativo (2003-2014), fenômeno ainda pouco provável para os próximos anos. De outra parte, revelou-se que o crescente contingente de trabalhadores autônomos também é dependente do andamento da economia e, dentro dela, da renda disponível de empresas e famílias.

Quanto à questão da informalidade, é preciso garantir a efetividade da legislação trabalhista no segmento assalariado, até porque a regulação tornou-se mais flexível e menos exigente.

De outra parte, já está claro também que, com o crescimento do volume de prestadores de serviços, é preciso que se estabeleça um tipo de regulação que atenda à instabilidade inerente à atividade e, ao mesmo tempo, contemple a natureza comercial que também parece caracterizar essa atividade. A possibilidade de que esses trabalhadores, na verdade, sejam assalariados disfarçados não é pequena, mas, dada toda a nova legislação, é inevitável ir além do seu enquadramento puro e simples e considerálos em suas especificidades. Assim, se, para o prevalecente trabalho assalariado, a informalidade significava o não cumprimento dos direitos e encargos trabalhistas, para o caso dos trabalhadores autônomos, essa questão resvala a sonegação ou fraude fiscal. Isso traz outra ordem de problemas com efeitos gerais, inclusive sobre a previdência social.

Outro aspecto importante das instituições do trabalho é a necessidade de um passo adiante para extensão de direitos trabalhistas como direitos sociais aos grupos ocupados não assalariados, ou informais, mas de alguma forma ocupados. Assim, coberturas ou direitos hoje associados ao trabalhador assalariado (e.g., auxílio-maternidade, previdência, acidentes de trabalho, qualificação profissional) também devem alcançar os ocupados não assalariados. Tal extensão contribuiria para a redução das desigualdades dentro do mercado de trabalho brasileiro se aplicada desde já e/ou no futuro.

Conforme Commons (1931), as instituições formam-se, ao longo do tempo, como uma ação coletiva que visa o controle, liberação e expansão da vida dos indivíduos. É certo que esse autor se contrapunha à visão mais estreita da economia liberal de que o trabalho fosse uma commodity qualquer a ser transacionada livremente nos mercados. Afinal, o trabalho não se dissocia daquele que trabalha. É certo também que sua formulação para as instituições do trabalho visava a estabilidade do mercado de trabalho pela interação regulada entre seus atores e maior progresso a partir daí.
Tendo isso em perspectiva, ainda em linha com as propostas da OIT, vale uma palavra pelo diálogo social como componente das instituições do trabalho no Brasil do futuro. Passado tanto tempo, mais do que nunca, isso soa válido para o caso brasileiro. O diálogo social pode auxiliar a busca criativa de alternativas para a regulação justa do mercado de trabalho e dar suporte à superação da conjuntura difícil dos últimos anos, ao seu aperfeiçoamento. Em síntese, ele seria útil na construção de um futuro com menos incerteza.

Até lá, sem descanso, Sísifo ainda empurrará a pedra montanha acima por muito tempo.

\section{NOTA DE AGRADECIMENTO}

O autor agradece a Fausto Augusto Junior pelo diálogo e sugestões.

\section{REFERÊNCIAS}

Adascalitei, D., \& Morano, C. P. (2015). Labour market reforms since the crisis: Drivers and consequences. International Labour Organisation, Research Department. Geneva, Switzerland: ILO.

Almeida, M. H. T. (1998). Sindicatos em tempos de reforma. São Paulo em Perspectiva, 12(1). Recuperado de http://produtos.seade.gov.br/ produtos/spp/v12no1/v12no1_01.pdf

Amorim, W. A. C. (2007). Greves no Brasil: Uma análise do período recente e tendências. In Amorim, W. A. C. (2015) Negociações coletivas no Brasil: 50 anos de aprendizado. São Paulo, SP: Atlas.

Amorim, W. A. C. (2007), A evolução das organizações de apoio às entidades sindicais brasileiras: Um estudo sob a lente da aprendizagem organizacional (Tese de doutorado, FEA USP).

Arbix, G., Salerno, M. S., Zancul, E., Amaral, G., \& Lins, L. M. (2017, novembro). Novos estudos. Cebrap, 36(3), 29-49.

Barbosa, A. F. (2008). A formação do mercado de trabalho no Brasil. São Paulo, SP: Alameda.

Cardoso, A. (2014). Os sindicatos no Brasil. Boletim Mercado de Trabalho: Conjuntura e Análise - IPEA, 20(56), 21-27.

Commons, J. R. (1931). Institutional economics. American Economic Review, 21, 648-657.

Confederação Nacional da Indústria. (2017). Modernização trabalhista: Lei $n^{0} 13.467$ de 13 de julho de 2017, panorama anterior e posterior à aprovação. Confederação Nacional da Indústria. Brasília, DF: CNI.

Dedecca, C. S. (2005). Notas sobre a evolução do mercado de trabalho no Brasil. Revista de Economia Política, 25(197), 94-111.

Departamento Intersindical de Estatística e Estudos Socioeconômicos. (2001). A situação do trabalho no Brasil. São Paulo, SP: DIEESE.

Departamento Intersindical de Estatística e Estudos Socioeconômicos. (2012). A situação do trabalho no Brasil na primeira década dos anos 2000. São Paulo, SP: DIEESE. 
Departamento Intersindical de Estatística e Estudos Socioeconômicos. (2017, maio). Relações de trabalho sem proteção: De volta ao período anterior a 1930? [Nota Técnica no 179].

Departamento Intersindical de Estatística e Estudos Socioeconômicos. (2020a). O Programa Emergencial de Manutenção do Emprego e da Renda diante dos impactos da Covid-19 [Nota Técnica no 232].

Departamento Intersindical de Estatística e Estudos Socioeconômicos. (2020b). Acordos negociados pelas entidades sindicais para enfrentar a pandemia do coronavírus - Covid 19 [Estudos e Pesquisas $\mathrm{n}^{0}$ 91] .

Gremaud, A. P., Saes, F. A. M. de, \& Toneto, R. J. (1997). Formação econômica do Brasil. São Paulo, SP: Editora Atlas.

Instituto Brasileiro de Geografia e Estatística. (2020). Indicadores IBGE. Pesquisa Nacional por Amostra de Domicílios Contínua - PNAD Contínua. Principais destaques da evolução do mercado de trabalho no Brasil 2012-2019. Rio de Janeiro, RJ: IBGE.

International Labor Organization. (2019). Work for a brighter future. Global Commission on the Future of Work International Labour Office. Geneva, Switzerland: ILO.

Islam, G. The future(s) of work. RAE-Revista de Administração de Empresas, 6o(5), 365-370. doi: 10.1590/So034-759020200506
Krein, D. (2018). O desmonte dos direitos, as novas configurações do trabalho e o esvaziamento da ação coletiva: Consequências da reforma trabalhista. Tempo Social, 30(1), 77-104. doi: 10.11606/01032070.ts.2018.138082

Ministério do Emprego e Trabalho. (2011). I Conferência Nacional de Emprego e Trabalho Decente. Brasília, DF.

Ministério do Emprego e Trabalho, Federação do Comércio do Estado de São Paulo. (2017). Contratos: $O$ que o empregador deve saber. Brasília, DF; São Paulo, SP.

North, D. C. (1991). Institutions. The Journal of Economic Perspectives, 5(1), 97-112. doi: 10.1257/jep.5.1.97

Philips, K., \& Eamets, R. (2007). Approaches to flexicurity: EU models. European foundations for the improvement of living and conditions of life. Dublin, Ireland.

Pochmann, M. (2010). Desenvolvimento, trabalho e renda no Brasil: Avanços recentes no emprego e na distribuição dos rendimentos. São Paulo, SP: Editora Fundação Perseu Abramo.

Polanyi, K. (2012). A grande transformação. Rio de Janeiro, RJ: Elsevier.

Sen, A. (2010). Desenvolvimento como liberdade. São Paulo, SP: Companhia das Letras.

\section{CONTRIBUIÇÃO DO AUTOR}

O autor declara que realizou todas as etapas de desenvolvimento do estudo. Desde a conceitualização e abordagem teóricametodológica, bem como na revisão teórica (levantamento de literatura), e, por fim, redação e revisão final do artigo. 